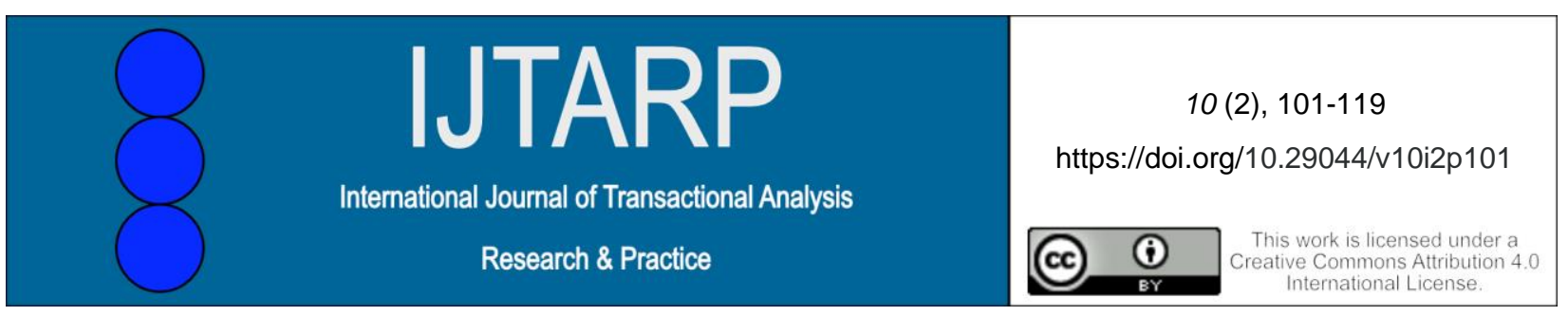

\title{
TA Contributions from India
}

\author{
(c) 2019 Julie Hay
}

\begin{abstract}
Produced originally as the content for an opening speech and associated workshop at the ITAA/SAATA Conference in Kochi, India in August 2018, the following contains a review of theoretical contributions from authors based in India between 1993 and 2018. In particular, the wide-ranging contributions of Os Summerton and Pearl Drego are described, along with a review of the activities of Father George Kandathil and of others on the subjects of the guru, ethics, universal consciousness and conflict strategies. Two themes are extracted: practical ideas and models, and the cultural and spiritual nature of Indian society, with an expansion of Berne's concept of autonomy into five components that are linked to Indian philosophy.
\end{abstract}

\section{Key Words}

autonomy, conflict strategies, cultural parent, cultural shadow, ethics, ethnic child, guru, India, transactional analysis, universal consciousness, Vipassana

\section{Introduction}

This material was prepared for the inaugural speech and a following workshop at the international Transactional Analysis Association (ITAA) and South Asian Association of Transactional Analysis (SAATA) joint conference in Kochi, India in August 2018. In the event, there were serious floods in the region and I was unable to proceed beyond Mumbai airport. Afterwards, I recorded the opening speech and made it available to the participants, and now generally, on YouTube at https://youtu.be/TVeLO8JleTM.

I was invited to give the opening speech because I had been involved with the TA community in India since I had served as ITAA President 1990-1991. As President, I had received and presented an offer to the ITAA Board of Trustees to host the 1993 ITAA conference in India. Since then, I have visited India many times, running TA training in many locations, attending further conferences, taking part in multi-level learnings, and running Training Endorsement Workshops including one in January 2018.
In addition to professional activities, I have ridden astride an elephant in a parade, been taught to wear a sari, visited many varied places of worship, cooked dosas on a big griddle at a conference, engaged in numerous tourist activities, and made many friends within the TA community.

\section{Years Ago}

I began my preparation for the inaugural speech by looking back 25 years, when I realised that I still had my copy of the conference proceedings from 1993.

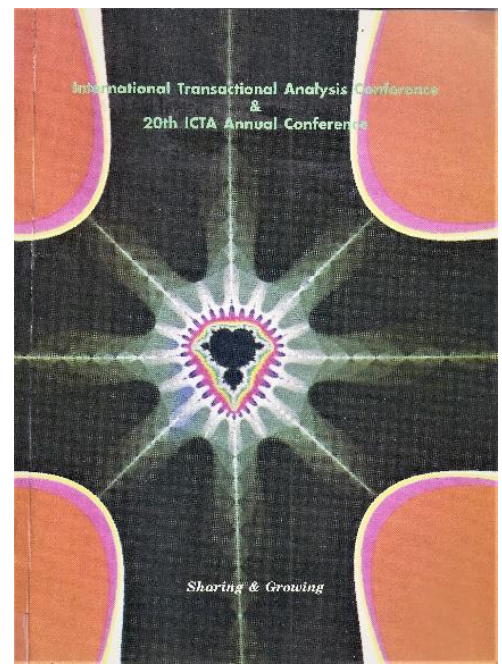

Conference Proceedings 1993

The theme was Sharing and Growing. Sr Annie Maria wrote about organising the conference, Fr George Kandathil about the conference theme, there were workshops on education, industry, management, rural women, cancer patients, $P_{1}$, and PK Saru (1993) wrote about Vipassana, explaining how this centuries old Buddhist meditation technique has striking similarities with TA. Learning to observe without identifying self with sensations builds awareness, especially once we recognise the universal truth of impermanence and the transitory nature of feelings. Vipassana encourages awareness at a deeper spiritual level, so that a higher order of intimacy becomes possible. 


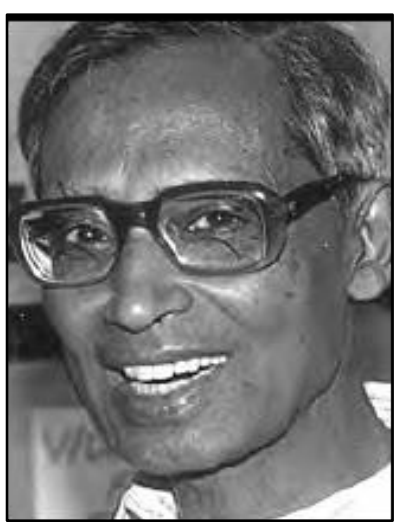

Dr George Kandathil

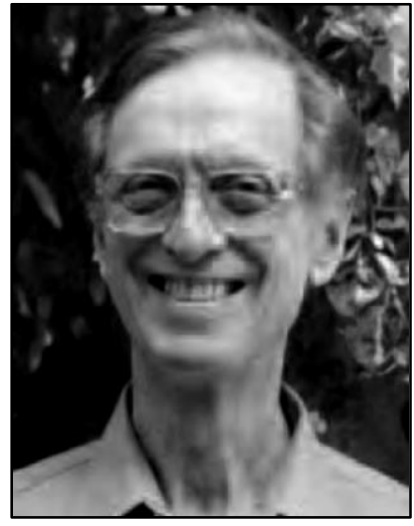

Oswald Summerton

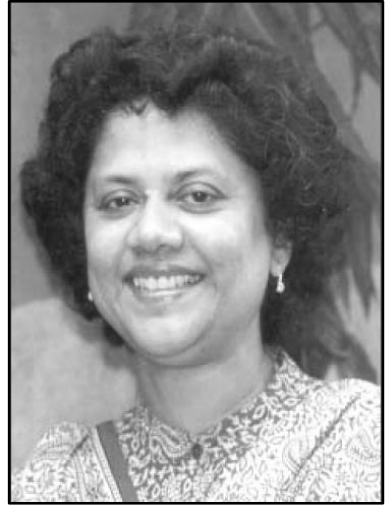

Pearl Drego

\section{Before 25 Years Ago}

Of course, to be hosting an international conference in 1993 meant that TA had already been thriving in India over many years. Fr George Kandathil (1910-2011) had trained with Muriel James and Claude Steiner and returned to begin teaching in India in 1971. In 1973 he initiated the Institute for Counselling and TA (ICTA). Soon afterwards, Fr Os Summerton (1926-2012) returned to India after training with Martha and Bill Holloway and Bob and Mary Goulding and in 1976 set up the TA Society of India (TASI) followed in 1980 by the Transactional Analytic Centre for Education, Research and Training (TACET). Pearl Drego was already there, completing a master's thesis in 1976 on script and injunctions.

\section{Father George}

Fr George then concentrated on getting TA out there, such that many became TA qualified and there is now the thriving TA community that has formed SAATA. In 1995 he co-authored a book aimed at the layperson (Kandathil, Kandathil \& Atthreya, 1995), and 2 years later $\mathrm{Fr}$ George and $\mathrm{Sr}$ Candida (Kandathil \& Kandathil, 1997) wrote about autonomy as an open door to spirituality, which they described as "the process by which human beings transcend themselves. For those who believe in God, spirituality is their experience of this relationship with God. For a humanist, spirituality is a self-transcending experience with another person. For some it may be the experience of harmony or oneness with the universe or nature in whatever way we describe it." (p.28).

I have often thought that I'm OK, You're OK is the equivalent of the TA religious belief - can you claim to be a TA practitioner if you don't believe it? Yet constructivist TA, and neuroscience, tell us that we construct our world: the film The Matrix, and some scientists, claim that it is all constructed. Some of you may be familiar with the way in which I have extended life positions into windows on the world, with a metaphorical non-distorting open window for I and
You. As I prepared this material, I was intrigued to realise as an atheist just how much my approach to TA has been influenced by Jesuits. The TA $101 \mathrm{I}$ attended in the 1970s was run by Michael Reddy, who had left a Jesuit monastic order after learning TA. Fr George and Os Summerton were both Jesuit priests who created TA associations that emphasised they were for, respectively "different traditions of religion, race and region" (ICTA) and "Hindus, Christians, Muslims, Sikhs and Parsis" (TASI). Bearing in mind that the originator of TA was Jewish, I invite you to think about how much TA for you is intermingled with religion and how much it is captured in the Kandathil and Kandathil comment that "when autonomy and intimacy blend in a person, he or she transcends himself or herself and rises to a new level of experience. This level of experience is what we mean by spirituality. Human love is the seed from which spirituality grows, and it is the fruit of spirituality as well." (p.29).

\section{Os Summerton \\ RANI}

When I began to look at what Os Summerton had written, I was aware of his many papers about psychological games. However, before that I saw that he had written about RANI (Summerton, 1979), which he used as an acronym for Relationship Analysis Instrument. This was based on what he regarded as the most common stroking combinations between people, of Parents to Parent, Adult to Adult, Child to Child, Parent to Child, and Child to Parent. He described positive strokes as pleasant and supportive of the individual and negative strokes as unpleasant and destructive of the individual. He pointed out that in his experience strokes were rarely clearly conditional or unconditional, although he then used $U$ and $C$ to suggest four stroking combinations which he described colloquially as:

- $\quad+U+C=I$ like you and I like what you do.

- $\quad+U-C=$ I like you and I do not like what you do. 
- $\quad U+C=$ I don't like you but I like the way you do things.

- $\quad \mathrm{U}-\mathrm{C}=\mathrm{I}$ neither like you nor what you do." (p.116) (bullets added).

He went on to relate these to Berne's (1961) four relationship possibilities: Sympathy - get along well together; Antagonism - enjoy fighting or arguing with each other; Antipathy - cannot stand each other; and Indifference -have nothing to say to each other. He linked these with symbols to the stroking combinations as shown in Figure 1.

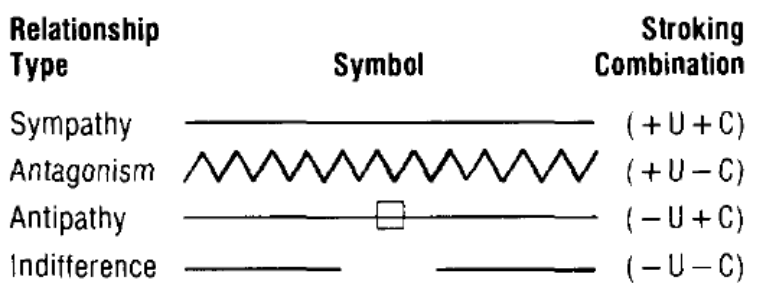

Figure 1: Relationship Qualities (Summerton, 1979, p. 116)

Summerton went on to provide some examples of how clients have used the Instrument to identify where they wish to change their relationships, such as Santosh who decided to ask for and listen to his wife's opinions in the Parent to Parent interaction. He recommended that weightings are applied so that clients concentrate on one change at a time. He suggested that partners complete the Instrument individually before comparing notes, and that sometimes it may be necessary to consider $2^{\text {nd }}$ order functioning in terms of Nurturing or Controlling Parent, Adapted or Free Child.

Parental Flip

Following that, I found his material on the Parental Flip (Summerton, date unknown, 1986). In his papers on this, he described how individuals under stress would flip from their own Child into their Parent ego state, usually in a way that meant they then attacked another person. He also identified how there might be 'complementary' parental flips, as shown in Figure 2.

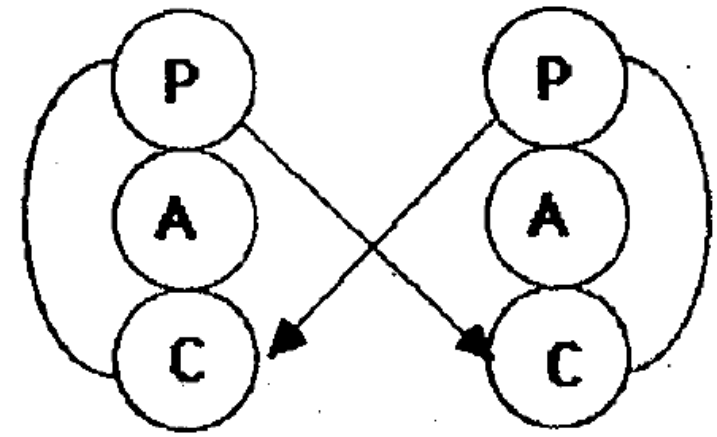

Figure 2: The Parental Flip in Action (Summerton, date unknown, p.109)
Rainbow Specs

Another early concept that I have found is Rainbow Specs (Summerton (1988, 1992a, 1993a). Prompted by the different colour thinking hats written about by Edward De Bono (1985), Summerton suggested that using the same metaphor for ego states might make the concept easier for clients to relate to, which is what he found. He emphasised that the colour indicates that each ego state has an attitude associated with it, to which the individual assigns a certain value. Changing colours then becomes an analogy for redistributing cathexis. Using Drego's (1979) subdivision of Adult into Photographic and Combining, Summerton then suggested the following colour codes for seven ego states:

$$
\begin{aligned}
& \text { Red - Natural Child } \\
& \text { Orange - Nurturing Parent } \\
& \text { Yellow - Photographic Adult } \\
& \text { Green - Combining Adult } \\
& \text { Blue - Controlling Parent } \\
& \text { Indigo - Rebellious Child } \\
& \text { Violet - Adapted Child }
\end{aligned}
$$

It was fun to see a note in the 1993a article that a rainbow card had been distributed with the previous version of the article. The arc of a rainbow had been overlaid with the three circles for the ego states and two quotations had been included: "I have set my bow in the clouds - a sign of the contract between me and earth" (Book of Genesis), and "Thou art a rainbow from the distant sky bending o'er the dust." (Rabindranath Tagore)." (Summerton, 1993 a, p.33-34).

\section{Models of Games}

From 1992, Os Summerton contributed many papers on games to the TAJ, culminating with Figure 3 that summarised different models of games in terms of duplex transactions, the payoff, and parental strokes. In these he included Berne's (1958) initial transactional model and (Berne, 1972) Formula G; the Goulding and Kupfer (Goulding, 1972) focus on inner perceptions; Kahler's (Kahler \& Capers, 1974) miniscript; Karpman's (1968) drama triangle; Schiff \& Contributors (1975) redefining hexagon; and English's (1977) focus on strokes and psychological racketeering. He then added non-TA author Shaffer's (1970) application of game dynamics to groups and communities rather than individuals, followed by his own game pentagon showing the five social roles.

\section{Game Pentagon}

For the Game Pentagon, Summerton (1992b) emphasised that the roles on this are social slots into which people can be expected to fit, and which may have negative or positive connotations. 


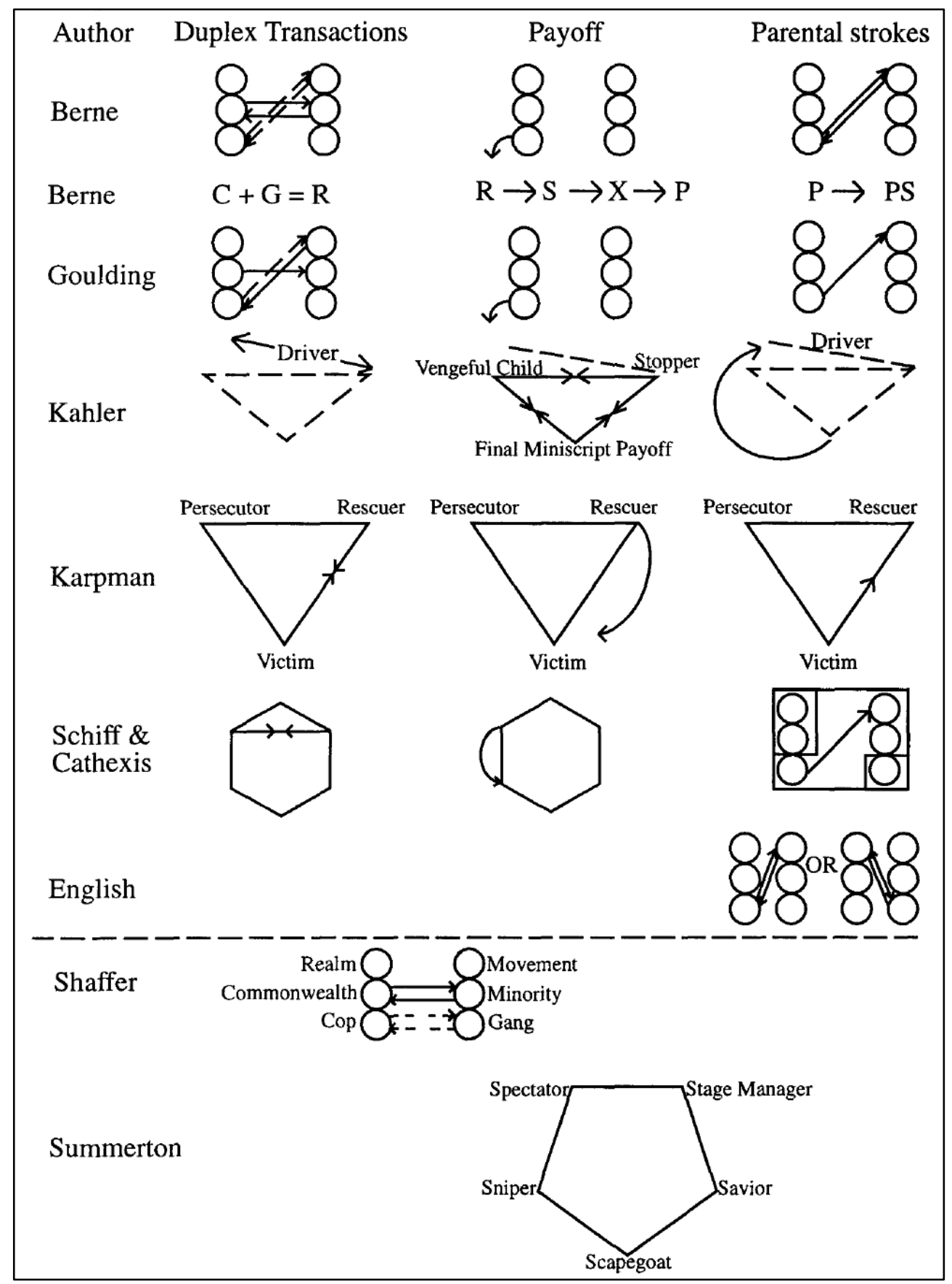

Figure 3: Summary of Game Models (Summerton, 2000, p.215)

See Figure 4 for the links between these roles:

- Stage Manager - the originator or source of an event, who unconsciously sets up the scenario or consciously masterminds it - such individuals may be forgotten because they do not appear on the scene of dramatic events.

- $\quad$ Spectator - the audience, the one who sits back and appears to be uninvolved but provides support by appearing interested in the event.
- $\quad$ Sniper - the openly decisive person, who may attack, defend, protect or prune, and offers critical comments and put-downs.

- Saviour - the ombudsman who brings justice, saves others from harm, takes up social causes.

- Scapegoat - who bears blame for others or suffers consequences on behalf or because of the group. 


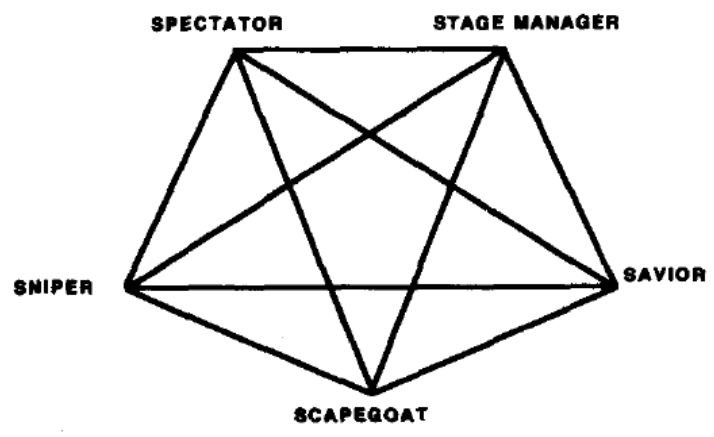

Figure 4: Game Pentagon (Summerton, 1992, p.69)

Soon after (Summerton, 1992c) he extended this to consider the two planes of intrapsychic and social, crediting Goulding and Kupfer (Goulding, 1972) with developing a way to analyse the intrapsychic processes of an individual and contrasting this with Berne's (1972) focus on the social situation. Summerton illustrated this as shown in Figure 5 by showing the Kupfer-Goulding model in a vertical plane alongside a horizontal plane containing Berne's Transactional Model.

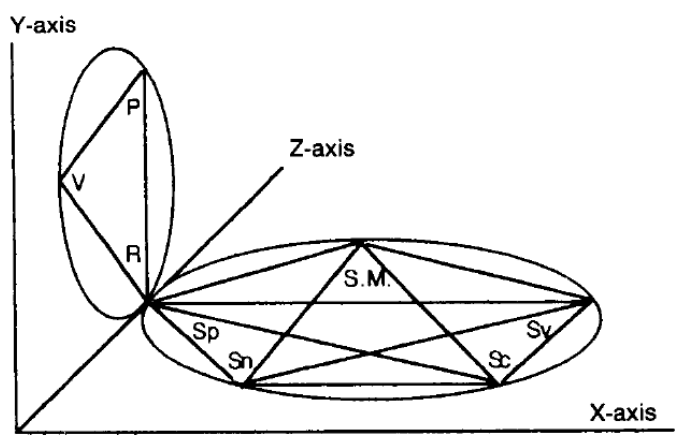

Figure 5: Two Planes of Game Analysis (Summerton, 1993b, p.31)
Not long after (Summerton, 1993b) he suggested a three-dimensional model using the drama triangle and the game pentagon, as shown as Figure 6. By now, he was also showing the game pentagon with drama triangles for each of the positions, indicating that we have four options: we are able to be in any of the roles on the game pentagon and behave competently, or we may do so in Persecutor, Rescuer or Victim role.

Summerton added that he saw Berne's "minor roles in script drama" (Berne, 1972, p.188) of Connection as merged with Stage Manager, Patsy with Saviour, Dummy with Spectator, and 'It' with Scapegoat. He added that rescuer, persecutor and victim without initial capitals are linked with Saviour, Sniper and Scapegoat, presumably in the positive version for that plane. In summary, the pentagon is of the positive or negative roles which are played in a group whereas the drama triangle roles relate to the individual - for instance, someone who ends as Victim within a psychological game may carry that position with them and end up being Scapegoated in a group.

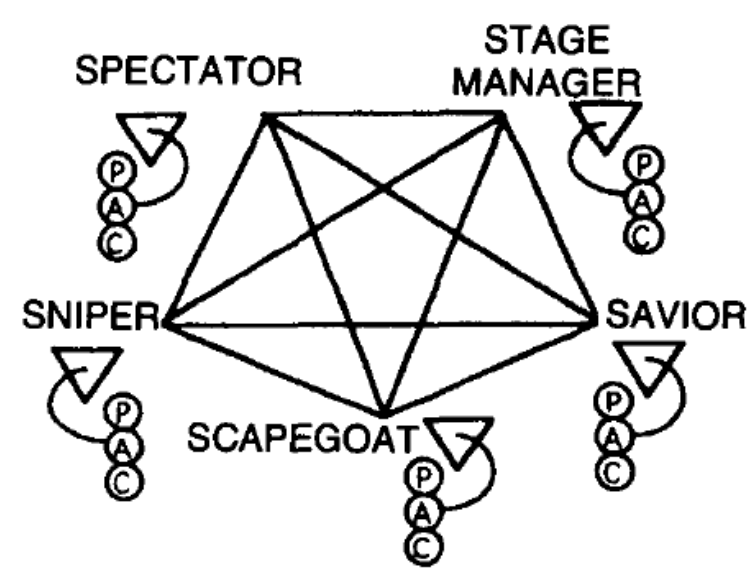

Figure 6: Diagram of the Individual on the Drama Triangle and the Game Pentagon (Summerton, 1993b, p.33)
(2)

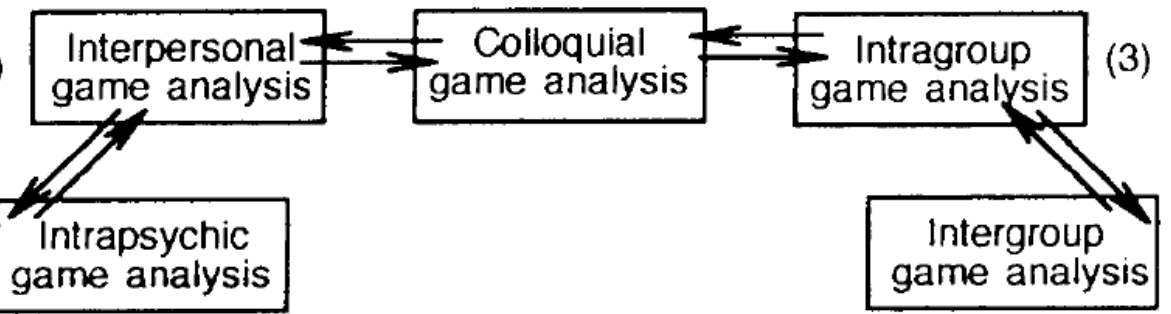

(4)
(1): Individual psychiatry
(2): Social psychiatry

(1) \& (2) : Individual dynamics
(3) \& (4) : Social dynamics

Figure 7: Game Spectrum (Summerton 1993c p. 88) 


\section{Game Spectrum}

Summerton (1993c) also proposed that more attention be paid to analysing games within organisations on the basis of intragroup and intergroup dynamics rather than on interpersonal and intrapsychic factors. He suggested a 'game spectrum' (Figure 7) which showed how intrapsychic game analysis linked to interpersonal game analysis, which in turn linked to colloquial game analysis, with the mirror image of that leading to intragroup game analysis and hence to intergroup analysis. Summerton explained that the distinctions he was making were important to ensure that the organisational dynamics were considered and that individuals were not scapegoated by considering games only from the point of view of the individual player.

He went on to give a case study example of a joint family business with the husband as the chairman, the wife as the executive director, two sons were partners in the venture and several cousins were also involved. A psychological game of 'I'm Only Trying to Help/Poor Me' ensued (the game names are as they appear from the points of view of the two players). Having analysed the dynamics at an interpersonal and intrapersonal level, the two players then joined the rest of the family in order to complete the intragroup game analysis. This is "... the sum total of interpersonal analyses of group members with each other, together with analysis of what is happening in the group as an organism, that is, the analysis of members' transactions with each other as a unit." (p. 92). This is reminiscent of Berne's (1964) three-handed and four-handed games and is needed to avoid scapegoating. It also alerts people to the fact that different members of the group will often replace each other within the same game dynamics.

In the example, Summerton uses his Game Pentagon (Summerton 1992b) and identified that "Rex moved from Stage Manager to Saviour to Victim, Regina from Saviour to Spectator, John from Victim to Sniper, Bruce from Sniper to Victim, Rick from Victim to Sniper." (p. 93). This quotation is included here to demonstrate the number of moves that may be occurring in such games. In the same example, Summerton illustrates intergroup analysis because an uncle had been invited to join in the intragroup analysis; this uncle was therefore an outsider to the organisation but it seems that he too became engaged in a game when his comments about the game playing were perceived as a criticism of the family group.

To illustrate the intergroup game, Summerton refers to Shaffer's (1970) Law and Order game, which was based on analysis of riots in the USA during the late 1960s. For this analysis, Shaffer diagrammed cultural ego states as circles that did not touch, and representing two kinds of societies - the dominant one with a monopoly on force and the subordinate one with the advantage of natural cohesion. He showed how the dominant society indicates that every opinion is respected whilst at the equivalent of an ulterior level the police are telling people who are protesting that they must leave, and that the subordinate society is overtly making a reasoned protest but covertly resisting the police. In other words, both groups appear to be interacting on an Adult-Adult level but a different message is being conveyed Child-Child at the psychological level.

Summerton also shows how the group culture of the family business can be shown in terms of etiquette we are the best; technicality - they award one plaque to one person, so that this person appears to be a favourite; and character - we are no good, we are fighting.

After some other examples, Summerton concluded by commenting that "the major difference between social psychiatry and social dynamics as understood by Berne (1963) is that the former focuses on managing unconscious manipulation, whereas the latter deals with the cultural matrices that support group games. In the effort to overcome group passivity, one important area would be to identify moral guidelines and alternatives in any society or organisation that can offset the impact of technicalities that are justifiable yet harmful." (p. 102).

\section{Upside-Down Rackets}

Summerton (1995) also developed a model of upsidedown rackets, presenting these in terms of a ladder as shown in Figure 8. These represent the pathway between a real feeling and an old racket feeling, which occurs when a person "phenomenologically changes the real feeling and its energy into a racket feeling." (p.215). As an example, someone feeling genuine tiredness may 'confuse' this with the racket feeling of tiredness that they were allowed when feeling anger was forbidden. Hence the tiredness is then experienced as if it is a substitute, or racket, feeling and a familiar trading stamp payoff is taken. Within the ladder, this example would mean that the real feeling of tiredness is on Rung 1; in childhood this was allowed instead of feeling angry, which is the forbidden feeling on Rung 2; Rung 3 becomes the racket feeling of tiredness; and Rung 4 will be the familiar payoff that applied in childhood. Understanding the sequence can be very helpful to individuals as they learn about their rackets and begin to allow themselves to experience genuine versions of what they only previously experienced as substitute feelings.

\section{Relationship and Group Analysis}

One final mention - years earlier Summerton (1978) had also suggested some additions to the four types of analysis suggested by Berne (1961). Berne had ego 


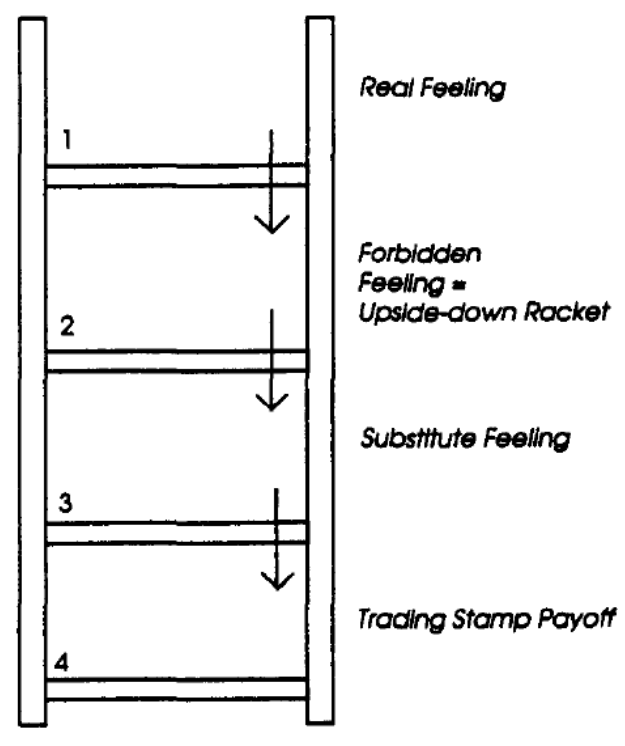

Figure 8: Upside-Down Racket Ladder (Summerton, 1995, p.219)

states, transactions, games and scripts. Summerton suggested we should add relationship analysis and the analysis of groups.

\section{Pearl Drego}

\section{Paradigms}

We can see the echoes of this when we look at Pearl Drego's work. Over the years, she has provided several articles about ego states. Referencing several prior publications (mainly conference presentations and books) Drego (1993) presented Berne's (1961, 1963) four principles of diagnosis to propose four corresponding paradigms, illustrating this with Berne's (1963) 'cowpoke story'. She provided a diagram to summarise Berne's models of phenomenological, historical, behavioural and social diagnosis, before presenting four more diagrams to illustrate how these become paradigms of experiential (for the phenomenological), biographical (for the historical), metaphorical (for behavioural) and relational (for social). Her diagrams for these paradigms are shown as Figures $9-13$.

\section{Different Perspectives}

Whilst writing about the four paradigms later, Drego (2000) proposed that "Each ego state is an integration from past and recent experiences..." (p. 192). She suggested that there is a need to develop an integrated Parent, integrated Adult, and integrated Child [initial capitals for the second word of each only in original]. For this, she pointed out that ego states can be considered as metaphorical and as real; that they are both transactional and intrapsychic; and they are archaic and yet also contemporary.
She added that different models will lead to different perspectives, providing the worksheet in Figure 14 for problem-solving using those different perspectives. Phenomenological models help us to focus on who we can be in the here and now; historical models help us focus on who we were in the past and how we carry positive and negative influences from the past; behavioural models help us focus on improving the quality of our communication, both within ourselves and with others; and social models aid us in maintaining equity, partnership and dignity in our relationships.

Adult Ego State

Within the 1993 paper, Drego also described the two aspects that had led her to label the two aspects for Adult ego state, referencing back to Drego (1979). She wrote that "the first aspect is called Photographic, which indicates the perceiving, appraising, representational, recording, categorising, and classifying ability of the Adult. The second is called Combining, which indicates the Adult's probability analysis, hypothesising, option-seeking, weighing of alternative courses of action, valuing, and decisionmaking abilities.... Berne (1970) mentioned two aspects of Adult: "taking in information from outside world, and deciding on the basis of reasonable probabilities what course of action to take" (p.105)." (Drego, 1983, p.20).

In 2000 she commented that she had found the "... dispassionate observer aspect of the Adult to be an ideal of harmony and self-actualisation that is consonant with mysticism and God-experience. The Indian spiritual ideal of being fully present in the here and now, without the effects of past karmas from this life or previous lives; the Buddhist ideal of selfawareness; the yogic ideal of dhyana or clear, unwavering attention; the classical Indian philosophical view of Being as consciousness and goodness; and the Christian experience of new life in Christ gives Berne's Adult ego state new dimensions of being and connectedness to deeper levels of reality." and "When transactional analysis supports the Adult in making a responsible choice based on a rational value, even though one is in the midst of emotional conflict from the Parent or Child, it seems to reinforce the values of the Bhagavad Gita of desireless actions or nishkarma karma. ... The Photographic Adult... provides an additional spiritual dimension as the witnessing self or see-er in Indian spirituality and has the same sense of noninterpretive, even-toned response to both intrapsychic reality and external reality." (p. 204) (italics in original).

Writing in The Script, Drego (2004) referred in the title of her article to constructing the Lost Parent. Although she does not go on to mention this term specifically 


\section{Phenomenological Model of Cowpoke Story Historical Model of Cowpoke Story}

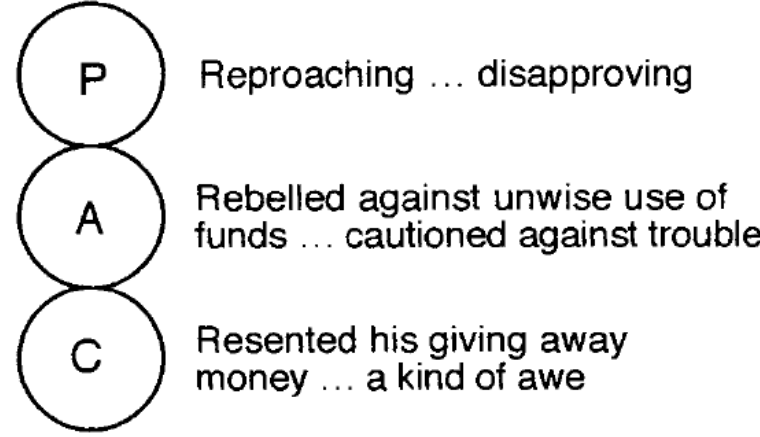

The subjective diagnosis is based on self-observation.

\section{Behavioral Model of Cowpoke Story}

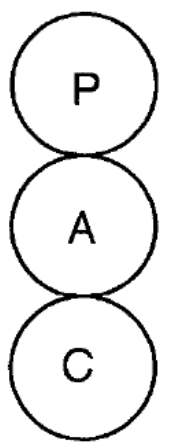

Sympathetic, philanthropic and helpful

Rational

Lonely and apprehensive

The behavioral diagnosis is made by observation.

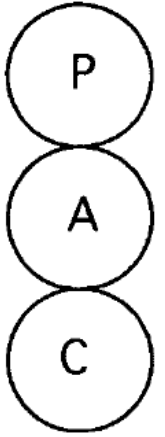

Duplication of his father's philanthropic attitude

Banker's shrewd foresight appraising the information offered by environment

Relics of the way he had behaved about money when he was a little boy

The historical diagnosis is made from factual information about the individual's past.

\section{Social Model of Cowpoke Story}

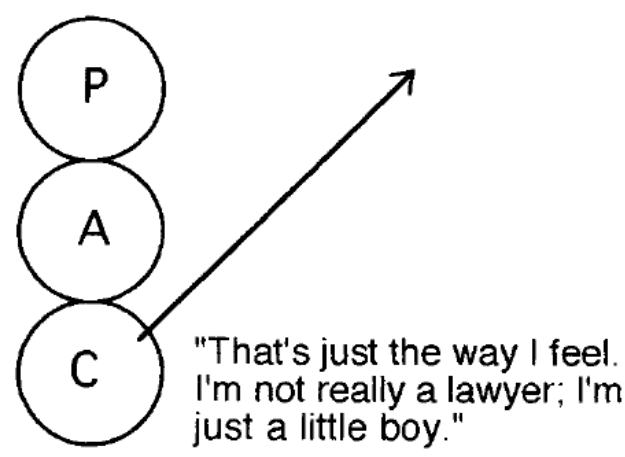

Those participating in transactions with the agent make the diagnosis on social grounds.

Figure 9: Ego State Models derived from the Four Paradigms of the Cowpoke Story (Drego, 1993, p.10)

\section{Experiential Paradigm}

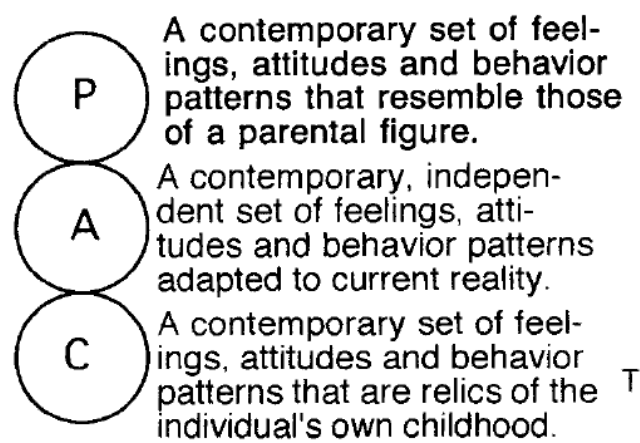

\section{Phenomenological Models}

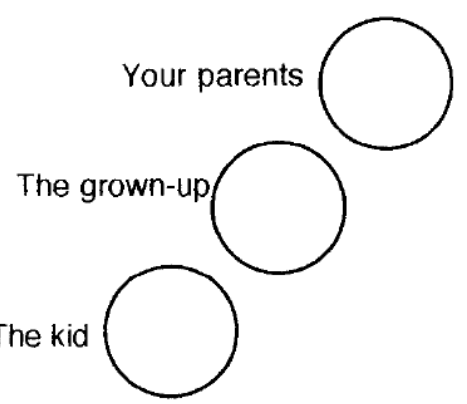

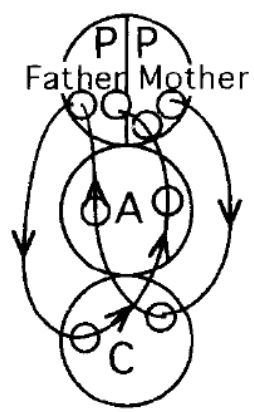

(Berne, 1963, pp. 136-137)

(Berne, 1961, p. 174, Figure 16(a)) (Berne, 1972, p. 252)

Figure 10: From Experiential Paradigm to Phenomenological Models (Drego, 1993, p.12) 


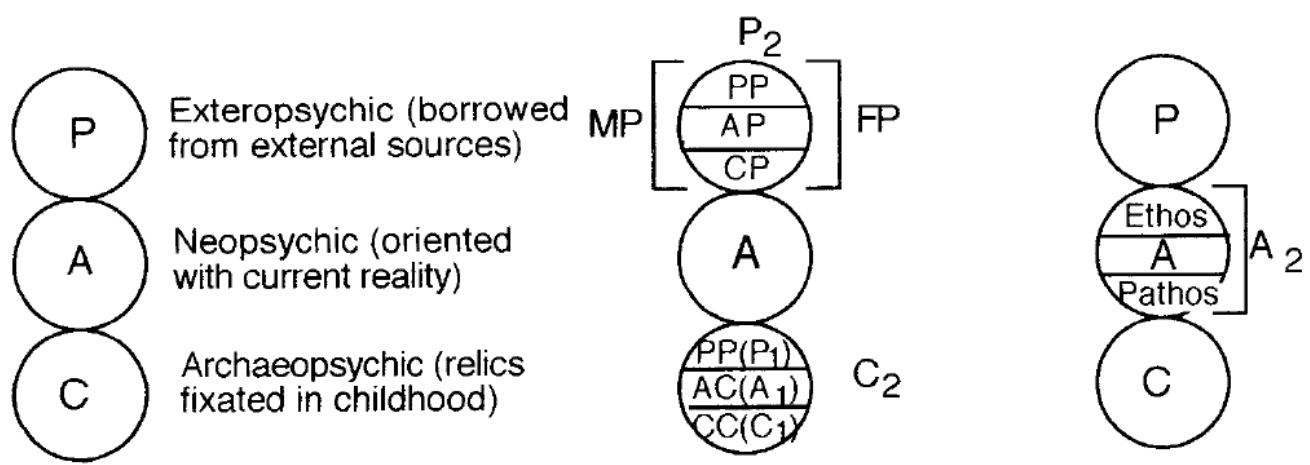

(Text : Berne, 1977, p. 146)

(Berne, 1969, p. 111) (Berne, 1961, p. 193)

Figure 11: From Biographical Paradigm to Historical Models (Drego, 1993, p.14)

\section{Metaphorical paradigm}

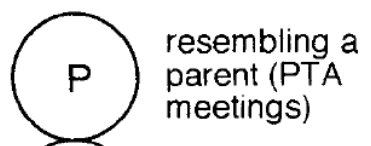

resembling a grown-up

A who deals objectively with facts (scientific meetings)

C resembling infants and young children of various ages

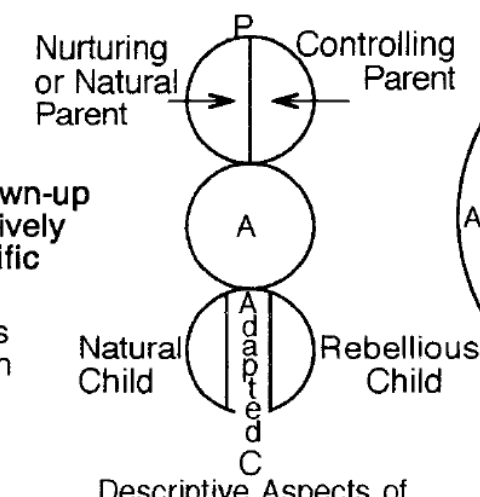

Descriptive Aspects of the Personality

(Berne, 1963, p. 130, 1961, p. 71)

(Berne, 1972, p. 13)
Behavioral Models

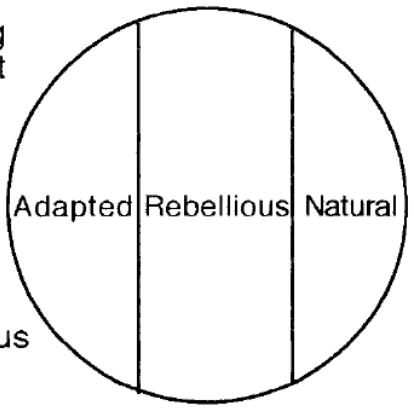

Descriptive Functions

(Berne, 1972, p. 412)

Figure 12: From Metaphorical Paradigm to Behavioural Models (Drego, 1993, p.17)

\section{Relational Paradigm}

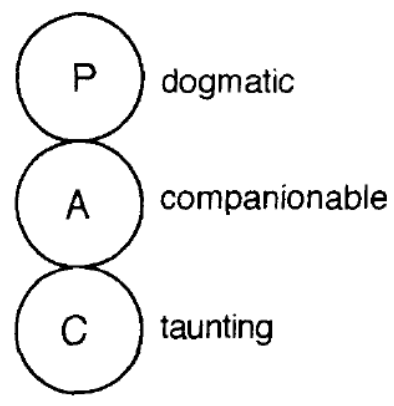

Clooney "I need you."

\section{Social Models}

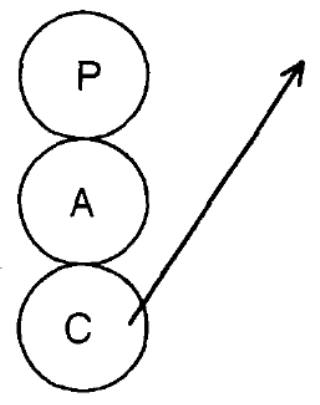

(Berne, 1977, p. 147) (Berne, 1972, p. 384) (Berne, 1970, p. 272) (Berne, 1970, p. 274)

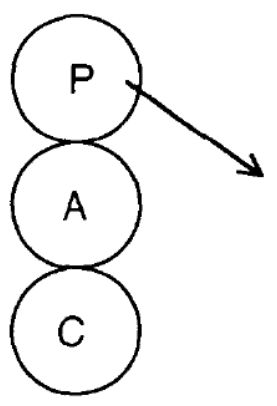

Bolsterer

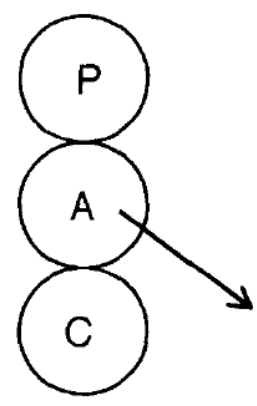

Advisor

Figure 13: From Relational Paradigm to Social Models (Drego, 1993, p.21) 


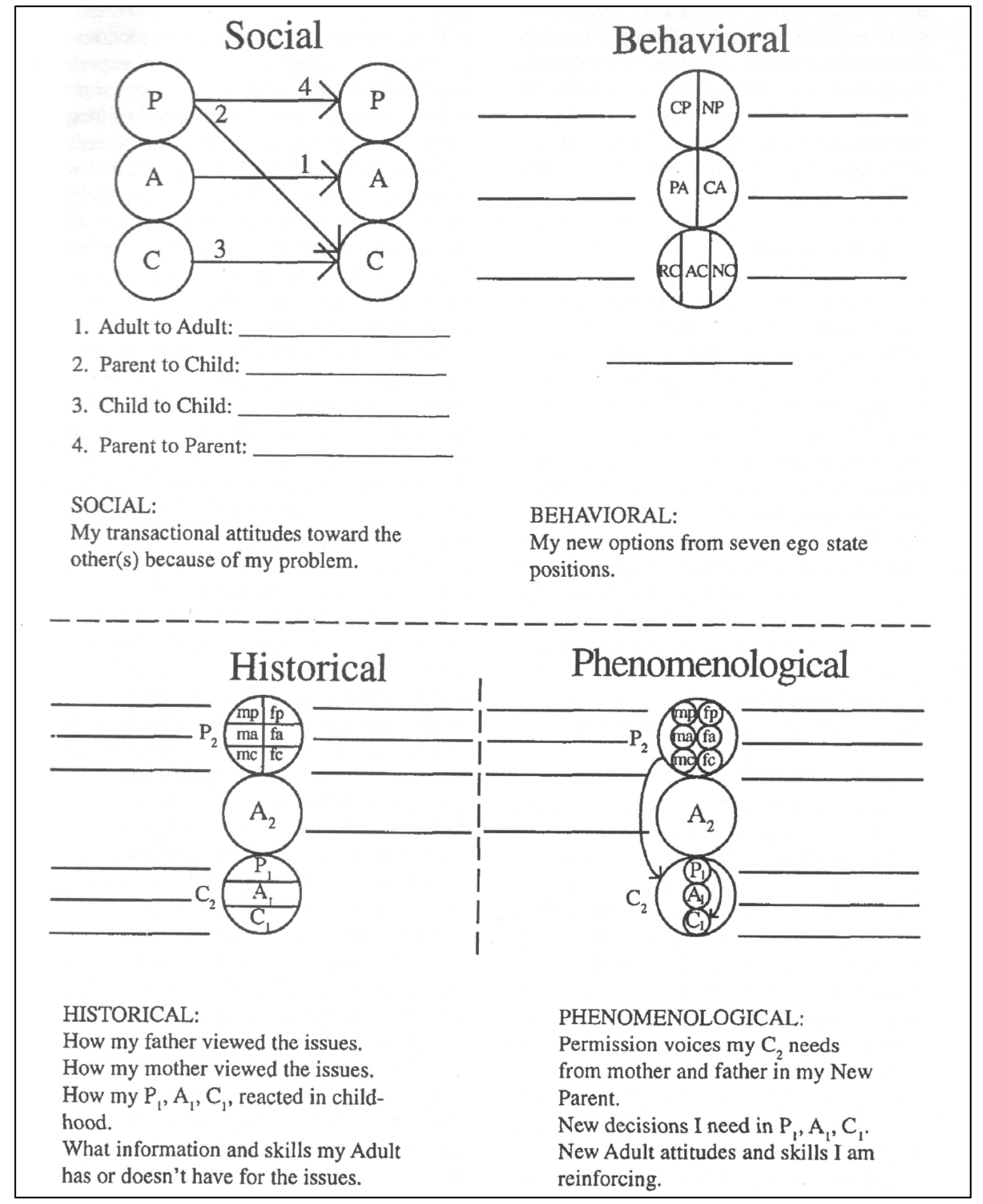

Figure 14: Ego State Models Worksheet for Problem Solving (Drego, 2000, p.200)

within the article, she writes that "The Parent ego state - the vehicle of hierarchies of autocratic power - has to submit to the reality-based lateral relationships of the Adult ego state. Commitment replaces domination, intimacy replaces predatory cultural relationships, strokes replace jealous competition and rivalry, and mutual planning replaces humiliating adaptations to authority." and "Hope is in the Adult ego state. When you have the facts and understand the scene, you can go beyond it." (p. 3).

Permissions

In her Acceptance Speech on receiving the 2004 Eric Berne Memorial Award, Drego (2005) drew together some of her material, including pointing out that relational/social and metaphorical/behavioural are 
functional diagrams whereas those for biographical/ historical and experiential/phenomenological are structural. She added that "... permissions can be felt in the Child on the social model, heard behaviourally as an active voice from a Nurturing Parent, and becomes phenomenologically a re-experience of the positive history of therapy." (p. 18). She added that she was particularly pleased about the Award "because it includes recognition of two new permissions that I introduced and that are important to the Indian ethos: the experience of God as expressed in the permission to Be Holy and the experience of community as expressed in the permission to Fight for Justice" (p.8). She added that there are corresponding injunctions and that the first permission is a challenge to arrogance and the second a challenge to narcissism, casteism, and exclusivism in our societies. The first is particularly significant as a permission for girls in India and the second encourages bonding.

Drego concludes this 2005 article with "giving and receiving permission changes who we are. The development of updated ego states empowered by permissions represents a journey of the human spirit, with tremendous capabilities for family and groups, a journey that can infuse us to bring peace into our lives, our communities, and our networking between communities." (p.29).

\section{Altruistic Model of Ego States}

A year later, Drego (2006) went on to propose an altruistic model of ego states within the phenomenological paragon, as shown below. She referenced Harris's (1967) comments about updated validated Parent data, updated Adult data and updated appropriate Child data, before commenting that "the process of updating and integrating Parent, Adult, and Child ego states engages the total personality in capacity building, by which qualities such as helpfulness, responsibility, compassion and caring, self-denial, and service flow abundantly and easily. Phenomenologically, we experience a new updated integrated Parent that has potency, a new updated integrated Adult that has responsibility, and a new updated integrated Child that has the security of inner freedom. Furthermore, as the intrapsychic attraction between ego states deepens, so does interpersonal connectivity with others." (p. 99).

\section{Cultural Parent}

Drego is of course known in particular for the introduction of the notion of the Cultural Parent, for which she suggested using ovals rather than circles to diagram the structure of the group culture, whilst using Berne's (1963) terms of etiquette related to Parent, technicalities related to Adult, and character related to Child, as shown in Figure 16. She (Drego, 1983) illustrated this with the example of the Indian dowry system, where the etiquette consists of beliefs about

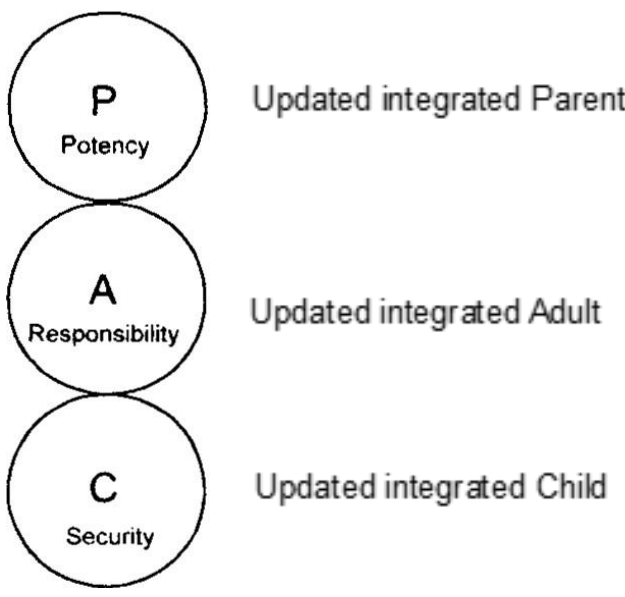

Figure 15: An Altruistic Model of Ego States (Drego, 2006, p.99)

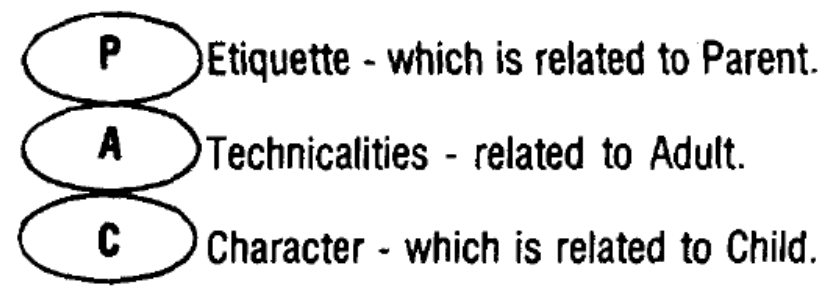

Figure 16: 'Personality' of a Culture (Drego, 1983, p.224)

women and their status in the original and the husband's family, the technicalities are the procedures for accomplishing the handing over of money or assets, and the character consists of the feelings of those involved (e.g. worth or worthlessness felt by the bride, power felt by the husband's family). She reminded us that the Cultural Parent exists within the individual and also within a community; in the latter case it is that which justifies and maintains the given social order.

Using similar examples from India, Drego went on to propose several examples that represent the Cultural Parent in action, including: children looking after younger siblings instead of going to school; wives been beaten by husbands; and believing oneself to be inferior because of the caste one is born into. She described the Cultural Parent as formed in the family and early sociocultural environment, and pointed out that the more closed the Parenting process, the fewer options allowed for the children. She also identified that movements to change the old structures may result in a reversal, quoting an example of China where children of farmers are encouraged to get a university education whereas the children of university graduates are denied this opportunity. 
Drego proposed that an unhealthy Cultural Parent is one which:

- $\quad$ keeps things the way they are and repeats history;

- takes on responsibilities for others unnecessarily;

- $\quad$ punishes change and new behaviours;

- maintains power and control over others, whatever it may take.

\section{Cultural Shadow}

Some years later (Drego, 1996) she illustrated how the culture of the group is echoed within the Parent of the individual's Child. She had completed a five-year interdisciplinary study where she had interviewed 273 women about injunctions, and realised that it was through injunctions that the women cooperated with their own subjugation. They had their own internalised Cultural Parent and Drego suggested that we might think of it as a Cultural Shadow within $\mathrm{P}_{1}$, just as Berne (1972) had referred to the negative electrode.

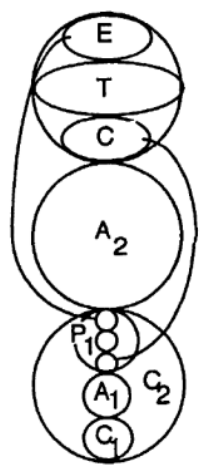

The Cultural Parent consists of Etiquette $(E)$, Technicality $(T)$, and Character (C). It is both an introject from family and community and an influence within the Parent $\left(P_{2}\right)$ that throws the Cultural Shadow onto the little Parent $\left(P_{1}\right)$ in the Child $\left(C_{2}\right)$.

Figure 17: Cultural Parent and Cultural Shadow (Drego, 1996, p.67)

She also pointed out that elements of culture may be in harmony or conflict: social slogans in the etiquette such as Work Hard may be reinforcing script injunctions of Don't Feel; alternatively "Character, like the rebellious Child, may impel the group in a direction opposite to the group's etiquette. Character can therefore sabotage the etiquette." (p.61).

Providing detailed information about the myths around Sita, an ideal woman with a life of great suffering and rejection; Savitri, who appears to be invincible but only in order to challenge for the good of her family; and Draupadi, who is gambled away by her five husbands (brothers), Drego commented that such myths are powerful reinforcements of the injunctions within families and cultures. She also provided information about other mythical stories that are commonly told and which all serve to create a culture in which women are expected to sacrifice themselves for others, and especially for their sons. Drego wrote that, with enough information, it is possible to bring the cultural injunctions into consciousness, and the Cultural Shadow into awareness. However, "to bring about a change, the oppressive Cultural Parent and its injunctions, myths, and reinforcements must be cleansed at the individual level as well as at the group level. Therapy with individuals needs to be supported by group discussions among mothers, group support systems among women, retraining programs for families, and new kinds of relationships between mothers and their children - in short a form of cultural therapy similar to one Erikson (1963) described: "'group therapy'of the kind which would not aim at psychiatric improvement of the individual participant but at an improvement of the cultural relations of those assembled" (p. 127)" (p. 74-75).

In addition to the material about the Altruistic model of ego states referred to above, Drego (2006) provided further material that had been presented as the closing keynote speech at the World TA conference 2005 in Scotland, where she had praised what she regarded as the Scottish Cultural Parent:

"Etiquette: We are all equal and we have the right to be free.

Technicality: Each person is responsible to state an opinion and to participate.

Character: You can't force me." (p. 96).

She based this conclusion on factors in previous centuries such as that the first act of freeing a slave "came through an $18^{\text {th }}$ century court order in Edinburgh that announced, "Nothing can change a rational creature into a piece of goods." (p. 90); the impact on women's emancipation and empowerment of the establishment of the first maternity hospital run by women; and the Covenanters' Bill of Rights which was ratified by all villages and counties and was sent to the king to demand people's self-determination.

\section{Ethnic Child}

Writing of yet another keynote speech, this time at the Transactional Analysis World Conference 2008 in South Africa, Drego (2009) extended her ideas about ego states and particularly the Cultural Parent, to propose an Ethnic Child. She began by describing four sources of inspiration: a march of over 20,000 women in 1956 to protest new laws requiring women to carry identity passes; the location of the conference in Africa with its amazing cultures and ecosystems; the contemporary ecological crises across the planet; and the vision of Eric Berne and other transactional analysts who work for societal change. She wrote that "I do not use "ethnic" to mean colored, first nation, or exotic. Every human child has ethnicity. We all have a biophysical ethnicity and a culturally conditioned ethnicity. It is the healthy parts of the latter that need to be identified, supported, and updated." and 
elsewhere "The Child in us is shaped by constructed culture as well as by natural ecological supports that are fast losing their significance in our lives. We can restore the historical roots of eco-culture within the Child and harmonize these with a contemporary earthcentred ethos so that we are authentically ethnic and ecologically modern. On this foundation we can harmonise the ethnicity of our ego states with our commonalities as children of the universe. In ego state terms, we update the lost ethnic Child to create a new contemporary ethnic Child. The people in a land such as South Africa, which has suffered from so much human and ecological trauma, will surely have depleted Parent ego states and will need to increase their energies for nurturing, caretaking, and protection through community action." (p.195)

Drego went on to quote her personal experience with a 10-year-old Indian child who was being excluded from school. After Drego had worked with her using a daily routine of strokes and encouragement of Adult, the child was then very successful in school. However, Drego comments on her own dismay when she realised that the child has now become "... ready prey and promoter of the Parent of noninclusive, unequal globalization." (p. 196) when the child showed that her favourite food has become a pouch of Heinz Tomato Sauce with some Lays chips, slices of Kraft cheese, and Nestlé chocolate. On the basis of this, Drego concluded "This experience made me reflect that the task of the transactional analyst in this context is to heal and empower the Child in such way that the best of ancestral tradition is transformed into a buffer against global stereotypes. We need a new updated ethnic Child who is guided by a healthy transformed ancestral Parent who integrates updated universal Parent values and is monitored by an Adult who carries responsibility for self and society (see Figure 1). This updated Child must learn to identify with ancestral culture as well as with contemporary, ecofriendly culture." (p. 196). Later, she added "While the globalised Cultural Parent can create internal splits for the ethnic Child, it can also be a way of dissolving ethnic identities into one melting pot of false universality." (p. 199)". We need to be able to see the difference between true internationality and consumerist global culture, and a world of a united humankind rather than the world of multilayered corporate interests. We need a universal Parent based on an altruistic model of ego states and geared therefore to ecological regeneration, so that "The ethnic Child becomes transformed into the "Illumined Child" bonding with the divine Parent." (p. 204).

She also pointed out that "... injustices and oppression is perpetrated against a minority cannot be redressed by the members of that minority because they have lost the sense of collective identity from which to master the show of strength and political power." (p.199).

\section{The Guru}

There have of course been various mentions of the guru and the Indian culture.

Sashi Chandran (2007) wrote of the Guru within as she described how trainees in supervision move to empowerment even though overadaptation is strongly reinforced by Indian culture, and hierarchical processes and the existence of gurus is very common. Explaining that 'guru' includes spiritual guide or leader, one respected for their knowledge and who gives advice, the container of wisdom and dispeller of ignorance, she also comments that the guru is intrinsic in everyone and likens it to physis (Berne, 1961). The guru is about balancing using each ego state rather than existing within one of them; supervision and training aimed at developing the guru within the supervisee is challenging for supervisees and supervisors.

A similar theme was picked up by Saru (2011) when she wrote of the need for some form of professional licensing whilst stressing that becoming a psychotherapist should be "an evolutionary process wherein the person reaches a balance in feeling, thinking, and behaviour .... the secure base a psychotherapist needs in order to deal with transference and countertransference issues..." (p.152). She refers to "the wholistic (sic) development of the individual: cognitive, affective, empathic, and spiritual" (p.152). Hence, although licensing is needed, it is no guarantee of competence and should not be done at the risk of losing the way in which the guru models whatever they need to teach as well as imparting information.

This theme of the context of India and the guru was continued when Rosemary Napper interviewed Saru, Annie Cariapa and Sailaja Manacha (Saru, Cariapa, Manacha with Napper, 2009). Saru pointed out that "India is one of the most ancient civilisations in the world. It has a unique fabric of cultural, social, ethnic, religious, linguistic, and economic plurality and diversity. In this context, multiple relationships were very much a part of my training as an early Certified Transactional Analyst in the Pioneer group in South India." (p.326). Relevant wherever TA is beginning to grow elsewhere in the world, the multiple relationships work because of the plurality of the ethnic fabric; the guru models rather than teaches which means that this comes from a place of conviction, growth and integration. What is passed on is what has worked, meaning there is a high degree of authenticity and that leads to trust. There are sometimes challenges due to the multiple roles, which makes contracting particularly 
important, but the key is integration - "in each of the roles... I bring certain aspects of my essence, of who I am, and all these aspects of who I am put together provide a powerful model to trainees when they see me as a trainer, a therapist, and a supervisor." (p.330).

\section{Ethics}

Continuing the theme of the Indian philosophical perspective, Suriyaprakash (2011) wrote of how his notion of ethics is influenced by dharma and karma. "Dharma has a wide spectrum of meaning, with basic duties on one end and the very nature of any being on the other. Between these two extremes are a range of meanings, including but not limited to righteousness, truthfulness, religion, code of conduct, morals, ethics, and values. Attempting to narrow the definition of dharma leads to oversimplification and hence defeats its purpose." (p.133). Suriya explained that karma is not fatalistic determinism; acting according to one's dharma earns good karma. He goes on to explain how the six paradigms shifts proposed by de Graaf and Levy (2011) are based on capitalism, democracy and individual development whilst Eastern cultures concentrate on collective well-being, respect for others and nature, and surrender to a larger force. Instead of moving from one polarity to another, we need to balance, whilst recognising that balancing is a continuous process.

Hence:

- the philosophy of "Vedanta emphasises the need to gain control and power over one's own senses and the importance of the means over the ends." (p.134)

- basing our decisions on dharma gives us "the power to shape our own destiny, which is intricately and inextricably interwoven with that of others around us, society at large, and the environment beyond." (p.134)

- The Bhagavad Gita "emphasises the need for us to transcend our narrow predicaments and act according to what is expected of us for the development of the larger system" (p.134)

- the Gita emphasises the need to act with the longterm in mind - and nature will find its own balance

- the Vedantic Sanatana dharma means "you are that" - self in its original form is the same in all of us and we are all parts of a larger whole, which in turn replenishes itself.

- The Upanishads (Roebuck, 2000) position ignorance as the result of attachment to material affairs and knowledge as the work of liberation from such attachment - this refers to the danger of believing we can know the right answer to an ethical dilemma.Universal Consciousness
This material was extended to include the Vedantic concepts of bhaman, atma, yoga and satchidananda (Suriyaprakash \& Geetha, 2014) in a psychophilosophical exploration of death and embracing eternity. "Brahman is universal consciousness, which is all pervasive, and we are perceived as a part of that whole. Hence, while atma (the soul) inhabits the body, the body is not the atma. So, when death occurs, there is a transition in which the atma sheds one body and at some point enters another body." (p.336). Hence within the Yoga Sutras, among others, death is inevitable but the atma is eternal. The authors also explain that yoga means union and karma can loosely be defined as voluntary action, so karma yoga means recognising the repercussions that could result from an action and maintaining detached attachment in which our likes and dislikes are momentary.

Satchidananda is proposed as physis realised. "Sat is truth, chid is the awareness of the truth, and ananda is the bliss experienced through the awareness of the truth. ... autonomy [therefore] could be understood as sat being the extension of spontaneity, as chid being the expansion of awareness, and as ananda being the experience of intimacy. .... this is how autonomy could be an "open door to spirituality"' (p.340) (italics in original).

Suriya and Geetha relate this to the Cultural Parent as shown in Figure 18. They also show, in Figure 19, how the process of spiritual contamination and fearing death is created, before giving some case examples of how this information can be useful within psychotherapy, educational and organisational practice.

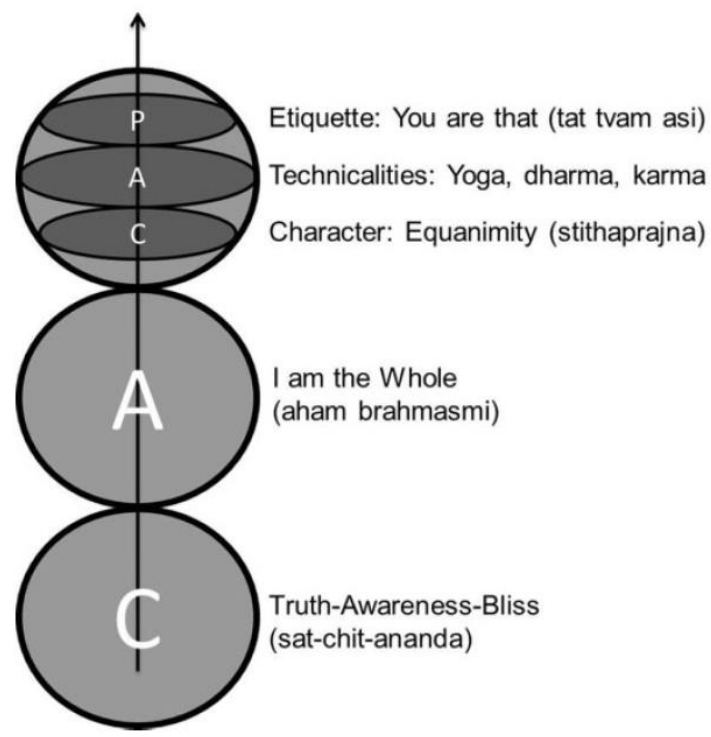

Figure 18: Spiritually Integrated Personality (Suriyaprakash \& Geetha, 2014, p.338) 


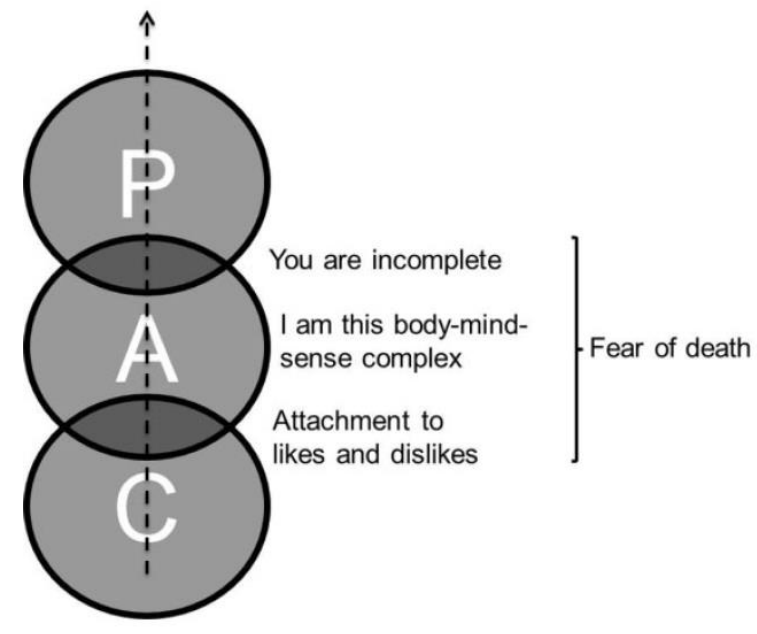

Figure 19: Spiritual Contamination and Fear of Death (Suriyaprakash \& Geetha, 2014, p.342)

\section{Conflict Strategies}

Having written in response to an article by de Graaf and Levy (2011), Suriyaprakash joined with Susan George (Suriyaprakash \& George, 2015) to respond to an article by de Graaf and Rosseau (2015) on the topic of how organisations respond to conflict. Commenting that they were inspired by de Graaf and Rosseau's comparison of the Thomas-Kilmann Conflict Mode Instrument (Thomas \& Kilmann, 1974) with the OK Corral (Ernst, 1971), and Morrison's (1978) living encounter positions, Suriyaprakash and George presented a grid in which they divide each quadrant of the OK Corral with a horizontal axis that refers to 'my convictions about my idea ( $\mathrm{M}+$ or $\mathrm{M}-)^{\prime}$ ' and a vertical axis referring to 'my convictions about your ideas $\left(\mathrm{Y}_{+}\right.$ or $\mathrm{Y}$-)', as shown in Figure 20.

They gave some examples from their own experiences, such as apparently irreconcilable differences between the ITAA and the erstwhile Training and Certification Council; training programs where trainees share their feedback on the learning process; people offering a TA 101 who are not qualified to do so; the Eric Berne Memorial Award selection process; and a lengthy conflict between an author and the TAJ editorial team. From these examples, they identify the need for cooperation, synergy, creativity and cooperation in order to arrive at consensus, which they then showed as in Figure 21.

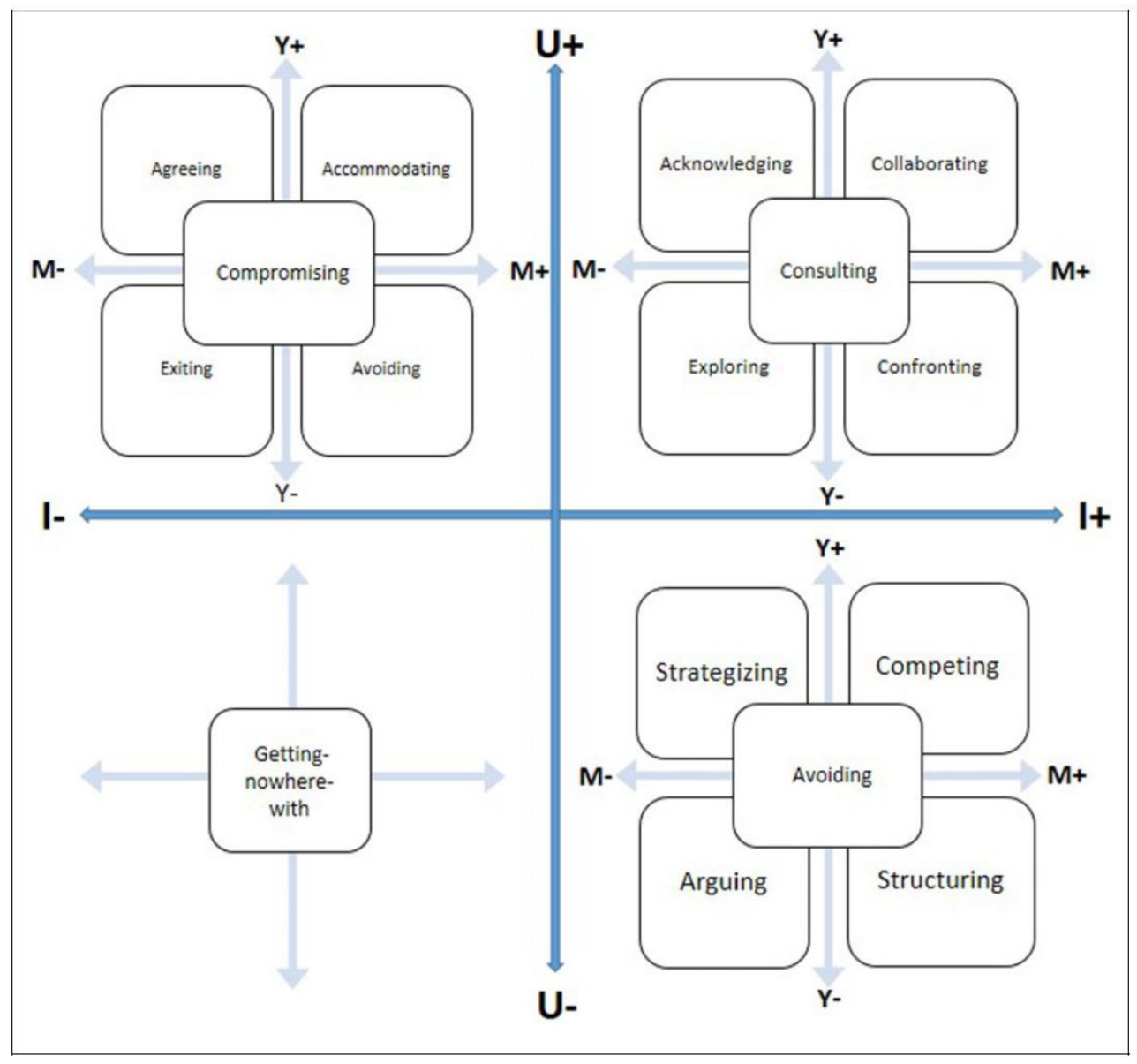

Figure 20: Conflict Strategies: Process (Suriyaprakash \& George, 2015, p.273) 


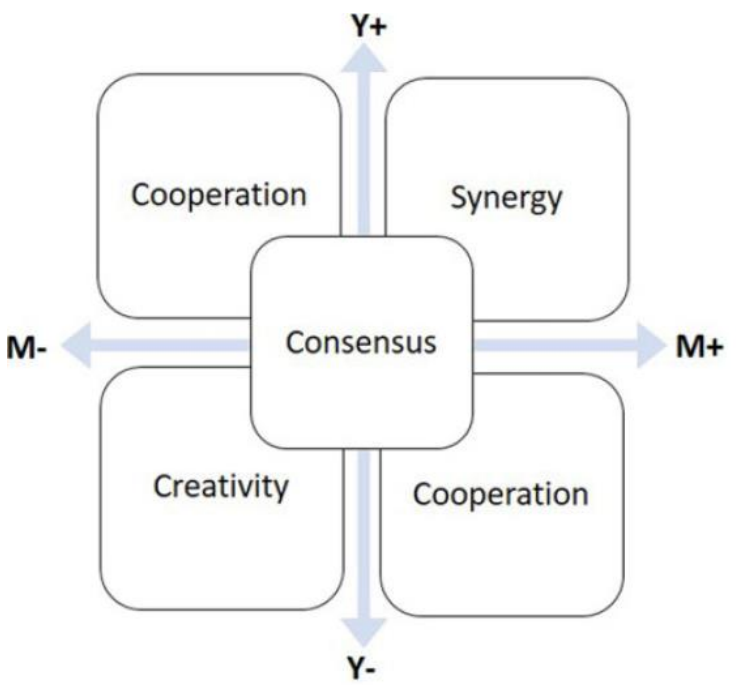

Figure 21: Conflict Strategies: Outcome for I'm OK, You're OK Life Position (Suriyaprakash \& George, 2015, p.274)

\section{A few more practical examples of what has been contributed.}

Bhattacharya, Chatterjee and Mukherjee (1994) describe the application of basic transactional analysis principles in a participatory management program for forest officials which resulted in those officials being able to successfully involve local village people in managing the forest. They link this to the drama triangle, game pentagon, and cultural script.

Viswanathan (1995) provided an interesting comparison of how Kaizen in daily life compares to TA.

Uma Rajgopal (1999) described a study of the patterns of behaviour of cancer caregivers in terms of drivers (Kahler, 1975).

More recently, Marina Rajan Joseph (2012) has written about the use of Berne's (1966) therapeutic operations within an educational context, and specifically for teaching.

The 3Ps Wheel

Uma Priya (2007) described harnessing the mind to facilitate a healing process, for a case in which the client was able to live each day meaningfully beyond the time indicated by the doctor's prognosis. She presented the $3 \mathrm{Ps}$ Wheel, in which the hub is the connecting point of mind and body, the circle represents the body, and the spokes represent the mind. The intervention therefore consisted of helping the client express pent-up emotions, using the 3 Ps Wheel to provide permissions, using progressive relaxation muscle technique alongside a visualisation of suppressed emotions being released, and using positive imagery about recovery alongside medical treatment.

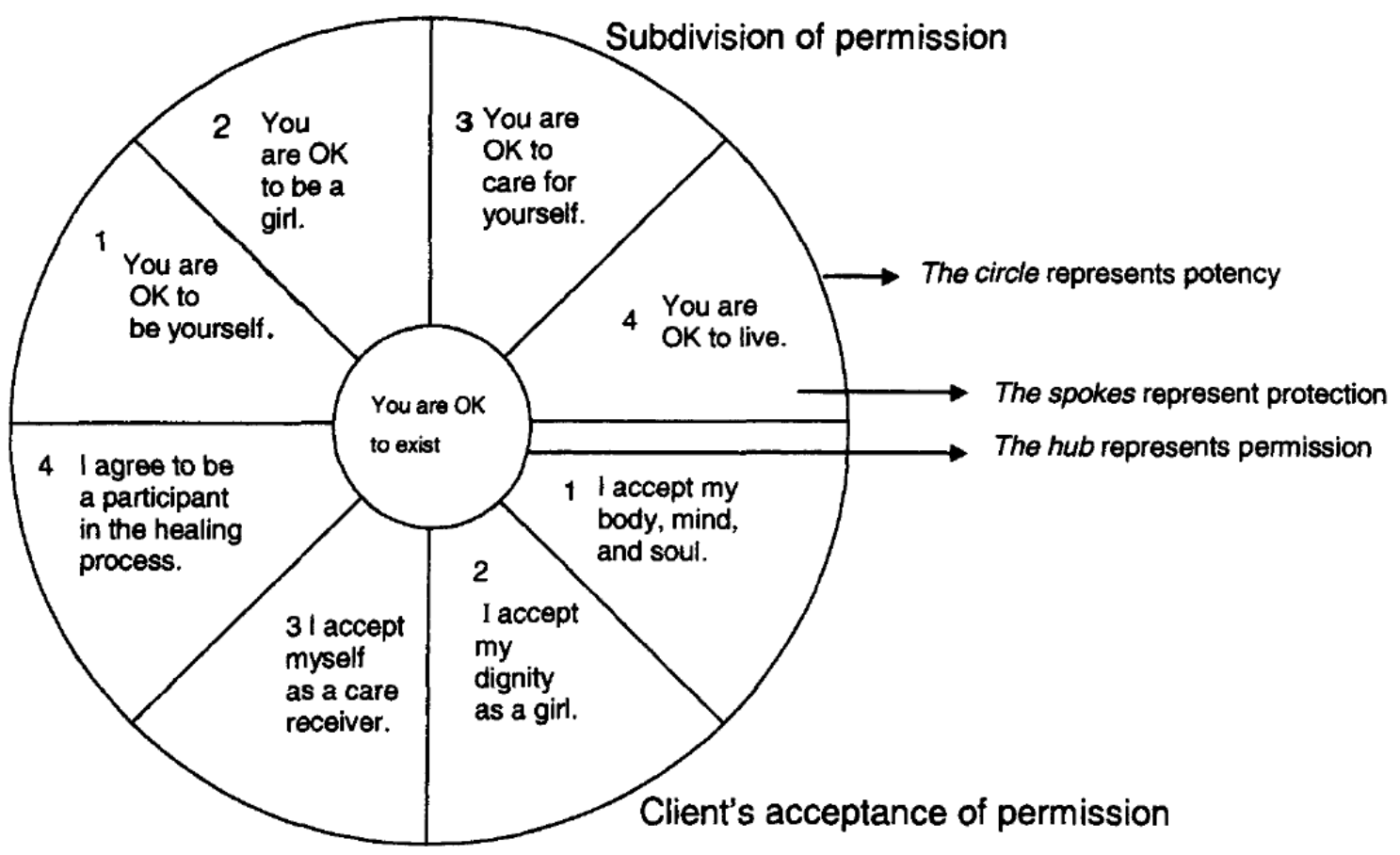

Figure 22: The 3 Ps Wheel (Priya, 2007, p.292) 
Imagoes

Suriyaprakash and Mohanraj (2008) developed the idea of a group transactional imago through the stages of:

1. A perceptual table, in which each group member checks for consistency between how I see myself, how I see you and how you see me.

2. The proportion of consistent to inconsistent perceptions is regarded as a measure of Individual Functional Effectiveness.

3. The Transactional Wheel represents this visually, with a participant in the middle and spokes indicating the strength of the relationship with each other person (thick lines for strong, thin for normal, dotted for weak or disrupted).

4. Scores of one for strong, half for normal and zero for weak or disrupted relationship yields a measure of Individual Transactional Effectiveness.

5. These can be combined into a functional matrix which then shows which ego states are being employed, so it can be seen who might be parenting the rest of the group, disrupting it through rebellion, or doing the logical thinking, or having the fun.

The use of ego states can be calculated to provide the Group Functional Effectiveness measure.

Suriyaprakash \& Raj (2003) had published some of this material previously although at that time they referred only to the Transactional Wheel and a Group Ego Matrix.

\section{Summary}

in summary, we might think of the contribution from India as within two themes:

- $\quad$ there have been many practical ideas and models

- there has been much arising from the cultural and spiritual nature of Indian society, particularly with reference to autonomy.

I have expanded Berne's (1972) three components of autonomy into five and below is how I linked these in to Indian philosophy:

- Awareness - we are all part of the whole

- Alternatives - we are not limited by past or present, - that is within our Parent ego state

- Attachment - this can be with God, nature, or with another person

- Authenticity - the guru passes on the lessons by modelling so we have absorbed the lessons ourselves
- Accountability - the principles of gurudakshina and rin apply - the former is that we have a fivefold debt to the gods, the spirits, our ancestors and teachers, to all living beings, and to trees, plants, forests, rivers and seas. Rin refers more specifically to the debt we have to our teachers which I am paying through how I pass on my TA knowledge as widely as possible, including many times pro bono.

\section{India}

I close with something prompted by Saroj Welch, who as a member of a conference panel about the role of permission (Allen, Allen, Barnes, Hibner, Krausz, Moiso, Welch \& Welch, 1996) pointed out that "There is no such entity as "Indian culture"! The 1971 census listed 1,652 languages as "mother tongues" spoken in India. These languages represent distinct cultures that have emerged from six main ethnic groups that have from centuries past moved onto the Indian subcontinent.... Each of these languages represents a distinct cultural group. Through the past 3000 years, some common cultural features have emerged for about $65 \%$ of people, even though there are distinct differences in each of the cultural groups." (p.200). The commonalities mentioned included: male dominance; females defined in relation to males; joint family system; marriages arranged by elders; individual identity is corporate as family, cast, clan and linguistic group; sex as an appetite to be satisfied like hunger and thirst, particularly by males, and procreation and child rearing are religiously sanctioned duties; every moment and stage of life is rigidly defined by myth and belief and deviations lead to severe intrapsychic and interpersonal suffering.

Google now shows a census in 2001 that has a few more languages - 1721 - and another entry tells us that the population in 2018 is 1.35 billion, which means that it has doubled in size over the last 40 years. One in six people in the world now live in India. It is great to see my Indian TA colleagues being so successful at sharing the benefits of TA with such a significant proportion of the world's population.

\section{Author}

Julie Hay MPhil MSc is a Teaching \& Supervising Transactional Analyst (Counselling, Organisational, Psychotherapy, Educational), the Editor of this journal, and a past president of EATA and ITAA. She can be contacted on julie@juliehay.org.

\section{References}

Allen, J., Allen, B., Barnes, G., Hibner, B., Krausz, R., Moiso, C., Welch, C. \& Welch, S. (1996). The Role of Permission: Two Decades Later, Transactional Analysis Journal, 26(3), 196-205.

https://doi.org/10.1177/036215379602600302 
Banga, M. (1996). Empowering Young Women Through the Use of Permission Cards, Transactional Analysis Journal, 26(1), 78-83. https://doi.org/10.1177/036215379602600112

Berne, E. (1958). Transactional Analysis: A New and Effective Method of Group Psychotherapy, American Journal of Psychotherapy, 12, 735-743. reprinted as Chapter 7 in Berne. (1977). Intuition and Ego States, San Francisco: Transactional Publications, 145-158. Ed. Paul Mc Cormick, publisher TA Press.

https://doi.org/10.1176/appi.psychotherapy.1958.12.4.735

Berne, E. (1961). Transactional Analysis in Psychotherapy, New York: Grove Press.

Berne, E. (1963). The Structure and Dynamics of Organisations and Groups, New York: Grove Press.

Berne, Eric (1970) Sex in Human Loving, New York: Simon and Schuster.

Berne, Eric. (1972) What Do You Say After You Say Hello? New York: Grove Press.

Bhattacharya, S. P., Chatterjee, M. \& Mukherjee, R. (1994). The Application of Transactional Analysis in a Participatory Forest Management Program, Transactional Analysis Journal, 24(4), 286-290.

https://doi.org/10.1177/036215379402400410

Chandramitra, R. (1996). Validating the Ethnic Metaphor. Transactional Analysis Journal, 26(1), 84-90. https://doi.org/10.1177/036215379602600113

Chandran, S. (2007). Connecting with the Guru Within: Supervision in the Indian Context, Transactional Analysis Journal, 37(3).

https://doi.org/10.1177/036215370703700306

De Bono, E. (1985). Six Thinking Hats, New York: Little Brown \& Co.

de Graaf, A., \& Levy, J. (2011). Business as Usual? Ethics in the Fast-Changing and Complex World of Organizations, Transactional Analysis Journal, 41(2), 123-128. https://doi.org/10.1177/036215371104100205

de Graaf, A., \& Rosseau, M. (2015). Transactional Analysis and Conflict Management: A Response, Transactional

Analysis Journal, 45(4), 250-259.

https://doi.org/10.1177/0362153715606171

Drego, P. (1979). Towards the Illumined Child - An Indian Study of Ego States, Bombay: The Grail.

Drego, P. (1981). Parenting in social process, TASI

Darshan, 1(6), 233-245.

Drego, P. (1983). The Cultural Parent, Transactional

Analysis Journal, 13(4), 224-227.

https://doi.org/10.1177/036215378301300404

Drego, P. (1985). The inner prison: A study of oppression of the Gujar women of Shantipur village, Unpublished doctoral thesis, Bombay University, Bombay, India.
Drego, P. (in press - in 1985 and 1996). The Inner Prison, Bombay: Alfreruby Publishers.

Drego, P. (1993). Paradigms and Models of Ego States,

Transactional Analysis Journal, 23(1), 5-29.

https://doi.org/10.1177/036215379302300102

Drego, P. (1994). Talk to me mum and dad: Permissions for young people, Bombay: Alfreruby Publishers.

Drego, P.(1996). Cultural Parent Oppression and Regeneration, Transactional Analysis Journal, 2(1), 58-77. https://doi.org/10.1177/036215379602600111

Drego, P. (2000). Toward an Ethic of Ego States,

Transactional Analysis Journal, 30(3), 192-206.

https://doi.org/10.1177/036215370003000304

Drego, P. (2004). Constructing the Lost Parent, The Script, 34(9), 3.

Drego, P. (2005). Acceptance Speech on Receiving the 2004 Eric Berne Memorial Award, Transactional Analysis Journal, 35(1), 7-30.

https://doi.org/10.1177/036215370503500104

Drego, P. (2006). Freedom and Responsibility: Social Empowerment and the Altruistic Model of Ego States, Transactional Analysis Journal, 36(2), 90-104. https://doi.org/10.1177/036215370603600203

Drego, P. (2009). Bonding the Ethnic Child with the Universal Parent: Strategies and Ethos of a Transactional Analysis Eco-Community Activist, Transactional Analysis Journal, 39(3), 193-206. https://doi.org/10.1177/036215370903900303

English, F. (1977). What shall I do Tomorrow? Reconceptualising Transactional Analysis, in Barnes, G. Ed, Transactional Analysis After Eric Berne, New York: Harper's College Press, Chap 15, 287-350.

Ernst F. (1971). The OK Corral; the grid for get-on-with Transactional Analysis Journal, 1(4), 231-240. https://doi.org/10.1177/036215377100100409

Goulding, R. (1972). New directions in transactional analysis In Sager \& Kaplan (eds), Progress in group and family therapy, New York: Bruner/Mazel, 105-134.

Harris, T. (1967). I'm OK, You're OK: A practical guide to transactional analysis, New York: Harper \& Row.

Hay, J. (2014). Extending the donkey bridge for autonomy IDTA Newsletter, 9(1), 8.

Joseph, M. R. (2012). Therapeutic Operations can be Educational Operations Too, Transactional Analysis Journal, 42(2), 110-117. https://doi.org/10.1177/036215371204200204

Kahler, T. (1975). Drivers: The Key to the Process of Scripts, Transactional Analysis Journal, 5(3), 280-284. https://doi.org/10.1177/036215377500500318 
Kahler, T, \& Capers, H. (1974). The Miniscript, Transactional Analysis Journal, 4(1), 26-42. https://doi.org/10.1177/036215377400400110

Kandathil, G. \& Kandathil, C. (1997). Autonomy: Open Door to Spirituality, Transactional Analysis Journal, 27(1), 24-29. https://doi.org/10.1177/036215379702700107

Kandathil, G., Kandathil, C., \& Atthreya, N. H. (1995). How to be Alert and Achieving: Success Secrets from TA Psychology, Bombay: Better Yourself Books.

Karpman, S. (1968). Fairy tales and script drama analysis, Transactional Analysis Bulletin, 7, 39-43.

Morrison, J. (1978). Conflict Management and the Living Encounter Positions, Transactional Analysis Journal, 8(3), 250-254. https://doi.org/10.1177/036215377800800321

Priya, R. U. (2007). Transactional Analysis and the Mind/Body Connection, Transactional Analysis Journal, 37(4), 286-293.

https://doi.org/10.1177/036215370703700406

Rajgopal, U. (1999). A Study of the Patterns of Behaviour of Cancer Care Givers, INTAND Newsletter, 7(2), 1-6.

Roebuck, V. J. (trans) (2000). The Upanishads, New Delhi: Penguin Books.

Saru, P.K. (1993). Vipassana TA Perspectives In, ITAA \& $20^{\text {th }}$ ICTA Annual Conference, ochin: ICTA 40-43.

Saru, P.K. (2011). Some Thoughts on the Licensing of Psychotherapists, Transactional Analysis Journal, 14(2), 151-153. https://doi.org/10.1177/036215371104100211

Saru, P.K., Cariapa, A., Manacha, S. \& Napper, R. (2009). India as a Unique Context for Developing Transactional Analysts, Transactional Analysis Journal, 39(4), 326-332. https://doi.org/10.1177/036215370903900409

Schiff, J. \& Contributors. (1975). Cathexis Reader: Transactional Analysis Treatment of Psychosis, New York: Harper \& Row.

Shaffer, T. L. (1970). The Law and Order Game, Transactional Analysis Bulletin, 9(34), 41-50.

Summerton, O. (date unknown). Beyond the Parental Flip, publication probably TASI Darshan, 107-112.

Summerton, O. (1978). The Bernian Grid, Transactional Analysis Journal, 8(1), 27-29.

https://doi.org/10.1177/036215377800800107

Summerton, O. (1979). RANI: A New Approach to

Relationship Analysis, Transactional Analysis Journal, 9(2), 115-118.

Summerton, O. (1986). The Rainbow Specs, Transactional Analysis Journal, 22(3), 182-188.

Summerton, O. (1988). The Rainbow Specs, TASI Darshan, 8, 181-192.
Summerton, O. (1992a). Rainbow Specs Rainbow Card publication, unknown.

https://doi.org/10.1177/036215379202200309

Summerton, O. (1992b). The Game Pentagon,

Transactional Analysis Journal, 22(2), 66-75.

https://doi.org/10.1177/036215379202200202

Summerton, O. (1992c). Game Analysis in Two Planes, Transactional Analysis Journal, 22(4), 210-215. https://doi.org/10.1177/036215379202200403

Summerton, O. (1993c). Games in Organisations, Transactional Analysis Journal, 23(2), 87-103. https://doi.org/10.1177/036215379302300206

Summerton, O. (1993a). Rainbow Specs Updated, TASI Darshan, 13(1), 26-34.

Summerton, O. (1993b). Three-Dimensional Transactional Analysis: The Drama Triangle and the Game Pentagon, Transactional Analysis Journal, 23(1), 30-35. https://doi.org/10.1177/036215379302300103

Summerton, O. (1995). Upside-Down Rackets, Transactional Analysis Journal, 25(3), 215-220. https://doi.org/10.1177/036215379502500305

Summerton, O. (2000). The Development of Game Analysis Transactional Analysis Journal, 30(3), 207-218. https://doi.org/10.1177/036215370003000305

Suriyaprakash, C. (2011). Ethics in Organizations: My Eastern Philosophical Perspective, Transactional Analysis Journal, 41(2), 133-135. https://doi.org/10.1177/036215371104100207

Suriyaprakash, C. \& Geetha, R. S. (2014). Embracing Eternity: A Psychophilosophical Exploration of Death from the Vedantic Frame of Reference, Transactional Analysis Journal, 44(4), 334-346.

https://doi.org/10.1177/0362153714560336

Suriyaprakash, C. \& George, S. (2015). The Many Facets of Conflict: People, Systems, and Causes, Transactional Analysis Journal, 45(4) 270-275.

https://doi.org/10.1177/0362153715608855

Suriyaprakash, C. \& Mohan Raj, I. A. (2008). Transactional Imago - a tool to study workplace communication as a medium of organisational culture, Johannesburg: Conference paper presented at Transactional Analysis World Conference 7-10 August 2008.

Suriyaprakash, C \& Mohan Raj, I. A. (2003). Internal Communication in a Group, INTAND Newsletter, 11(2), 1011.

Thomas, K. W. \& Kilmann R. H. (1974). Thomas-Kilmann Conflict Mode Instrument, Mountain View, CA: Xicom. https://doi.org/10.1037/t02326-000

Viswanathan, P. J. (1995). Kaizen in Daily Life, INTAD Newsletter, 3(2), 1-3. 